\title{
sciendo
}

\section{Impact of Internal Migration on Population Redistribution in Slovenia}

\author{
Samo Drobne, Urška Drešček \\ University of Ljubljana, Faculty of Civil and Geodetic Engineering, Ljubljana, \\ Slovenia
}

\section{Abstract}

Background: In most countries, data on migration refer only to flows between administratively or statistically defined zones that are changing over time. When different numbers, sizes, and shapes of areas are chosen for analysis of internal migration, different results are generated. This problem is recognised as the Modifiable Areal Unit Problem (MAUP). Objectives: The paper analyses the impact of intermunicipal migration on population redistribution in Slovenia in 2000-2014 by considering the MAUP. Namely, the number of analysed municipalities increased by 19 in the considered period. Methods/Approach: We analysed the MAUP effects and estimated internal migration statistics by producing a large number of aggregations using the IMAGE Studio software. Results: Several statistics that measure the direction and pace of population concentration, as well as the correlation between measures of migration intensity and national development, have been calculated. Conclusions: The results for Slovenia show that the migration efficiency decreases with the development process measured by the human development index.

Keywords: internal migration, MAUP, population redistribution, zonal aggregation JEL classification: C10, C43, C49, O 15

Paper type: Research article

Received: Apr 28, 2018

Accepted: Jan 03, 2019

Acknowledgments: The authors acknowledge the financial support from the Slovenian Research Agency (research core funding No. P2-0227 Geoinformation Infrastructure and Sustainable Spatial Development of Slovenia and research core funding No. P2-0406 Earth Observation and Geoinformatics).

Citation: Drobne, S., Drešček, U. (2019), "Impact of Internal Migration on Population Redistribution in Slovenia", Business Systems Research, Vol. 10, No. 2, pp. 49-60.

DOI: 10.2478/bsri-2019-017

\section{Introduction}

Bell et al. (2002) argued that migration is probably the most complex component of demographic change due to its multidimensional nature. For this reason, they suggested following four dimensions of migration, comprising migration intensity, impact, distance, and connectivity (Bernard et al., 2017). Bell et al. (2002) also proposed a series of robust metrics by which each facet of migration could be measured. 
Besides a selection of appropriate measures of internal migration, time-space frameworks on which the analysis is based are the key methodological issues in migration studies. Like in all other spatial-based studies, the analysis of migration data for different zonal systems is affected by the modifiable areal unit problem (MAUP). Namely, Openshaw (1984) proved that when different numbers, sizes, and shapes of zones are chosen for analysis of internal migration in any country or region, different results are generated.

Recently, a new software, the IMAGE Studio (Daras, 2014; Stillwell et al., 2014), was developed to compute a series of migration indicators and to explore the MAUP effects. The IMAGE Studio was already used in several recent studies to explore crossnational variations in internal migration with regard to overall intensities (Bell et al., 2015), age patterns (Bernard et al., 2014), population redistribution (Rees et al., 2016), and distance moved (Stillwell et al., 2016). They highlighted the substantial variations that exist between countries.

In this paper, we used the IMAGE Studio to analyse the migration propensities in Slovenia and their changes in a period of 15 years, i.e., from 2000 to 2014 . However, we report and discuss only selected results, mainly for the intensity of migration and the association between the migration efficiency and the development process in the country. Thus, we considered two research questions: How effective were internal migrations for a population redistribution in Slovenia during the period 2000-2014?; and: Is there an association between the efficiency of migration and human development in Slovenia, as reported by Rees et al. (2016)?

\section{Background}

\section{Changes of municipalities in Slovenia}

We analysed the impact of internal migration on population redistribution in Slovenia for the period between 2000 and 2014. In this study, solely inter-municipal migrations were analysed. Considering the analysed period, the number of municipalities in Slovenia changed four times. In 2000, there were 192 municipalities in Slovenia. In 2002, one new municipality was established. The second change happened in 2006 when 17 new municipalities were established. Consequently, the number of municipalities grew from 193 to 210. Later, two new municipalities were established, namely one in 2011 and another in 2012 (SORS, 2017a). However, due to a constitutional dispute, the last change was not recorded in the analysed statistical data. Therefore, the number of analysed municipalities grew by 19 municipalities, from 192 at the beginning to 211 at the end of the analysed period. Figure 1 shows the inter-municipal net-migration rate in 2016, the municipalities in Slovenia in 2016, and the newly established municipalities during the period 2002-2016.

Apart from the variation in the number of municipalities, there were also changes in statistical surveys and data dissemination over the analysed period. New breakdowns were introduced one year after the establishment of municipalities, which was in 2003, 2007, and 2012, respectively. Each breakdown was used from the beginning of the selected year on.

The change in the number (and the size and the shape) of the municipalities brought about the effects of the Modifiable Areal Unit Problem (MAUP), described in detail by Openshaw (1984). The MAUP includes the scale effect and the zonation effect. In the analysis (and models) of migration propensities and geographical flow patterns in different countries or regions, which have their own hierarchy of spatial units to collect, analyse, and disseminate migration data for research or planning purposes, the scale effect is identified by observing the change in an indicator (or 
model parameter) when the number of basic spatial units (BSUs; e.g., census and statistical zones, postal areas, settlements, municipalities, communities) changes, whereas the zonation effect, is identified by observing the indicator change when the number of BSUs remains the same, but the BSUs are configured differently (Stillwell et al., 2014). Here, the migration propensities were analysed for four different systems of municipalities in Slovenia.

Figure 1

Internal Net Migration between Municipalities in Slovenia in 2016 and New Municipalities Established in 2000-2016

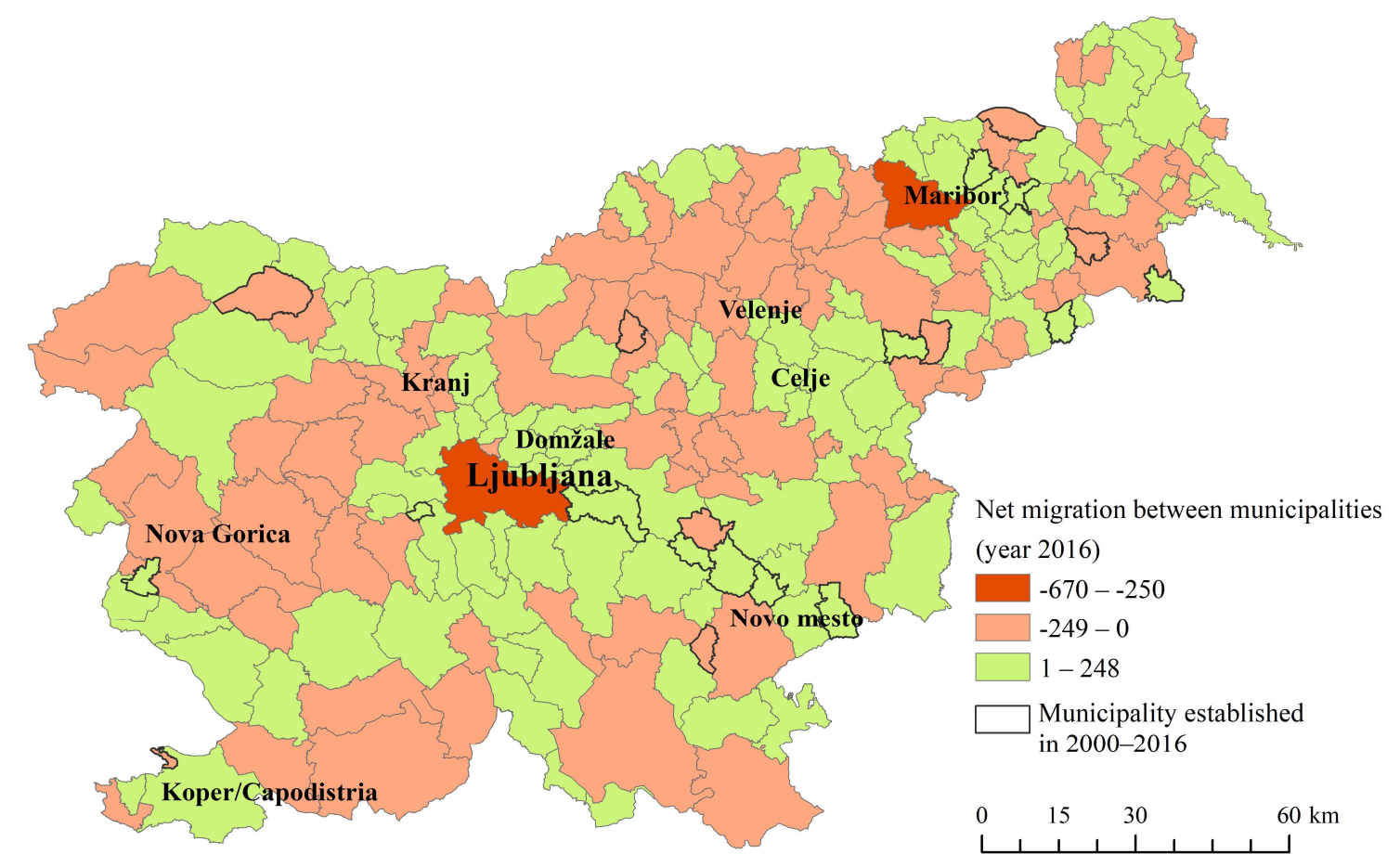

Source: SMA (2017), SORS (2017b).

Note: Municipalities with 30,000 inhabitants or more are denoted by names.

\section{Internal migration in Slovenia}

After World War II, internal migrations in Slovenia were significantly affected by deagrarization, industrialization, and urbanization, which caused strong migration pathways from the countryside to urban areas (UMAR, 2009). In the 1970s, several urban centres of Slovenia were developing rapidly, following the concept of polycentric urban and regional development. In that time, commuting was the prevailing substitute for migration. This was also a time when the volume of internal migrations among Slovenian settlements was high indeed, mostly at the expense of intensive home building industry (Bevc et al., 2004). At the beginning of the 1990s, the number of internal migrants decreased. In 1995, 147 smaller municipalities replaced the 64 previously large communities, which brought about the change in the structure of internal migration. The volume of inter-municipal migrations increased, while the volume of migrations between the settlements within the same municipality decreased; mostly, these migrations were newly considered as inter-municipal (UMAR, 2009).

In the period between 1995 and 2004, migrations between the municipalities of the same statistical region presented the largest part of internal migrations (approx. 40\%), 
followed by migrations between the settlements of the same municipality (approx. $35 \%$ ), while $25 \%$ were those between statistical regions (Bevc et al., 2004). The period between the 1991 and 2002 censuses is well known in Slovenia as a period of suburbanization. At that time, the number of inhabitants in towns of Slovenia declined by $3 \%$ on average and grew by $5 \%$ in suburban areas, mostly for the sake of migration processes (Ravbar, 2005). In the years 2005-2007, the number of internal migrants grew. In 2008, a sudden increase in the registered number of migrations can be detected (see Figure 2), which was primarily the consequence of the changed methodology of data collection on internal migrations of population. For the first time, the data on internal migrations of foreign citizens in Slovenia was published, using the same methodology as the one used for the citizens of Slovenia (SORS, 2017a). According to 2008 data, foreigners were more mobile than Slovenian citizens (Drobne et al., 2013). In 2009, app. 9\% fewer internal migrations were registered than in 2008. In 2010, the growth in the volume of internal migrations became evident again, and it remained growing until 2013. Then, along the years 2014-2016, the number of internal migrants declined. However, there is still a suburbanization tendency, especially around the two biggest cities of Slovenia, i.e., Ljubljana and Maribor; see Figure 1 for the 2016 situation. Figure 2 shows internal migrations between the municipalities of Slovenia during 2000-2016.

Figure 2

The Volume of Internal Migrations between Municipalities in Slovenia in 2000-2016

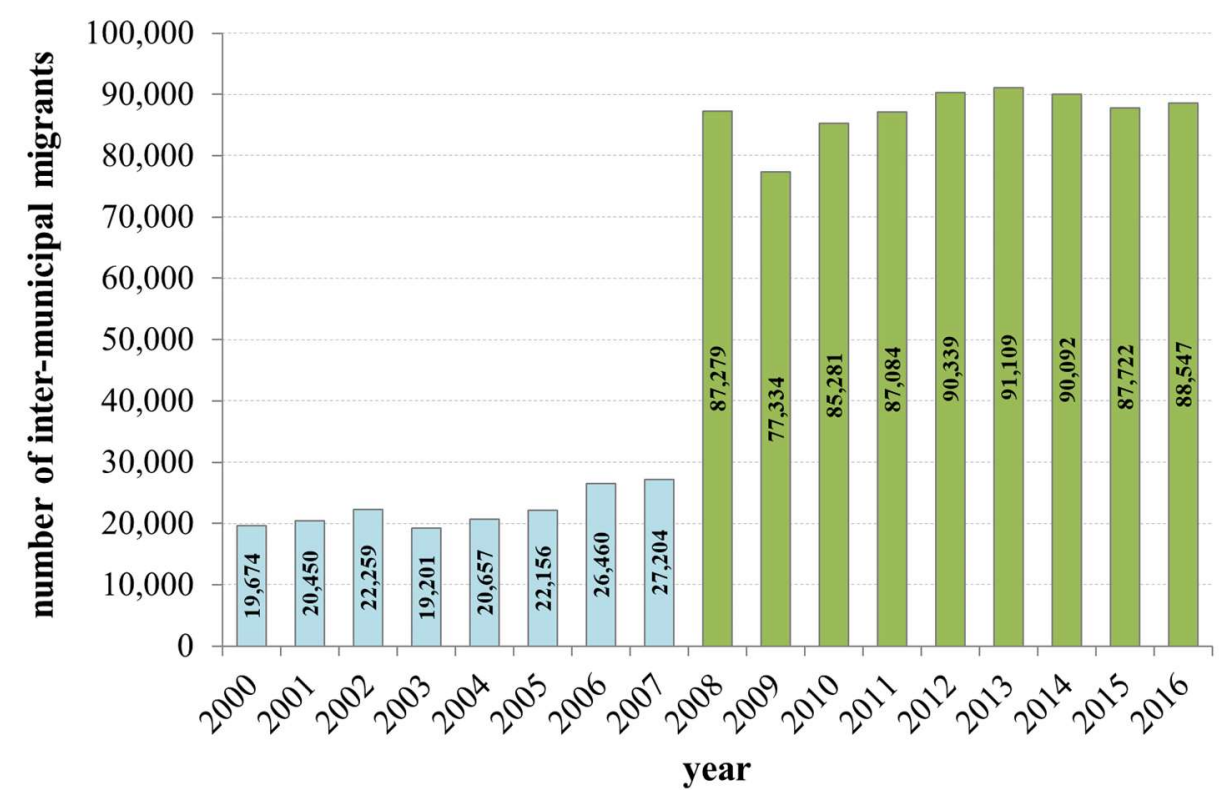

Source: SORS (2017b)

\section{Methodology}

The migration propensities between Slovenian municipalities were analysed for nine selected years of the 15-year period 2000-2014. Firstly, at the beginning and end of the analysed period, i.e., 2000 and 2014. Secondly, the year before and the year when at least one new municipality was considered in the statistical data, i.e., 2002 and 2003, 2006 and 2007, 2011 and 2012. Additionally, also in 2009 to analyse the period between 2007 and 2011 more consistently.

The data on migration between Slovenian municipalities were obtained from the Statistical Office of the Republic of Slovenia (SORS, 2017b), based on the Central Population Register. The problem arising from the data capture methodology in the 
database of migrations between municipalities was caused by the change in the methodology, which was introduced in 2008. Until and including 2007, only the citizens of Slovenia were included in the studies of internal migrations. Since 2008, all the inhabitants of the Republic of Slovenia, not exclusively its citizens, have been considered in the analyses of internal migrations (SORS, 2017a). This is why the data on the 2008-2014 migrations are no longer directly comparable to the 2000-2007 data. For this reason, the results are shown separately for these two periods.

Additionally, data on population in each municipality in a specific year were obtained from the Statistical Office of the Republic of Slovenia as well (SORS, 2017c). Data on municipal boundaries were obtained from the Surveying and Mapping Authority of the Republic of Slovenia (SMA, 2017).

In our research, the IMAGE Studio (Daras, 2014; Stillwell et al., 2014) was used to compute a series of migration indicators for each analysed year and to explore the MAUP effects. Some of these indicators depend on scale. For this reason, indicators for a cascading sequence of zonal aggregations were generated and subsequently analysed, beginning with the number of municipalities rounded by ten in each year, and progressively aggregating upwards in the increment of 10. At each spatial level, the algorithm created 100 of spatial configurations by stepwise aggregation of basic spatial units (BSUs; in our case municipalities) into aggregate spatial regions (ASRs) of varying shapes and sizes. A series of migration indicators proposed by Bell et al. (2002) was computed for each configuration at a given spatial level. The results were then averaged before repeating the process at the next level of aggregation. In this way, a sequence of migration indicators estimated for the selected levels of spatial aggregation was obtained. The change in the mean value of the indicator demonstrates the scale effect of the MAUP, while the variation around the mean reveals the zonation effect (Stillwell et al., 2014; Rees et al., 2016). Afterwards, migration indicators generated by the software IMAGE Studio that consider all four dimensions of migration, namely migration intensity, impact, distance, and connectivity, were computed and analysed. However, because of the page limit of this paper, we show and discuss only selected results of the analysis.

As suggested by Bell et al. (2002), the overall impact of net migration was captured on the pattern of spatial structure in Slovenia by the aggregate net migration rate (ANMR). ANMR is defined as half the sum of the absolute net changes aggregated across all regions, divided by the population at risk:

$$
A N M R=100 \times 0.5 \sum_{i}\left|D_{i}-O_{i}\right| / P
$$

where $D_{i}$ and $O_{i}$ are inflows to and outflows from ASRi, and $P$ is the population summed across all regions. The ANMR identifies the net shift of population between regions per hundred persons resident in the country, and thus measures the impact of migration on population redistribution. The $A N M R$ can be defined also as a product of the crude migration intensity $(C M I)$ and the migration effectiveness index (MEI):

$$
A N M R=C M I \times M E I / 100
$$

where:

$$
\begin{gathered}
C M I=100 \times M / P \\
M E I=100 \times 0.5 \sum_{i}\left|D_{i}-O_{i}\right| / M \\
M=\sum_{i} D_{i}=\sum_{i} O_{i}
\end{gathered}
$$

and $M$ is a total number of internal migrants. 
The CMI represents the level of internal migration within a country (the propensity to move), but the MEI indicates the efficiency of migration as a mechanism for population redistribution by comparing net migration with migration turnover. The MEI quantifies the spatial imbalance between migration flows and counter-flows. Low values of $\mathrm{MEl}$ are found when migration streams and counter-streams are closely balanced, while high values indicate asymmetry across the system, with some ASRs gaining population at the expense of others (Rees et al., 2016). Since the CMl and the ANMR are both dependent on the scale (Bernard et al., 2017), their mean values for 100 different aggregations were considered at all analysed spatial levels.

Bell et al. (2015) showed that there is a moderate association between migration intensity and a range of development indicators across 96 countries. They reported a significant inverse association between the mean MEI and the level of urbanisation, the Human Development Index (HDI), and GDP per capita. Rees et al. (2016) fitted the third-order polynomial (similar to inverted U-shape curve) to data on MEI and HDI for 47 countries all around the world and showed that MEI rose and then fell with development expressed by $\mathrm{HDI}$; see also Figure 5. In this paper, the correlation between mean MEI and HDI for Slovenia was analysed and compared for selected years between 2000 and 2014. Furthermore, the MEI and HDI for Slovenia were graphically compared with results for 47 countries, as provided by Rees et al. (2016). Data on HDI for Slovenia were obtained from UN (2017). In this paper, the development was analysed only by HDI rather than by GDP per capita, because HDI is a composite index of life expectancy, education, and per capita income indicators, which encompass GDP per capita as well (HDI, 2018).

\section{Results}

Table 1 shows the main statistics on migration between Slovenian municipalities in the analysed period.

Table 1

Main Statistics on Migration between Municipalities in Slovenia in 2000-2014

\begin{tabular}{llllllllll}
\hline Year & 2000 & 2002 & 2003 & 2006 & 2007 & 2009 & 2011 & 2012 & 2014 \\
\hline $\begin{array}{l}\text { Number of } \\
\text { municipalities }\end{array}$ & 192 & 192 & 193 & 193 & 210 & 210 & 210 & 211 & 211 \\
\hline $\begin{array}{l}\text { Population in } \\
\text { Slovenia }\end{array}$ & $\begin{array}{l}1,990, \\
094\end{array}$ & $\begin{array}{l}1,995, \\
718\end{array}$ & $\begin{array}{l}1,996 \\
773\end{array}$ & $\begin{array}{l}2,008, \\
516\end{array}$ & $\begin{array}{l}2,019 \\
406\end{array}$ & $\begin{array}{l}2,042, \\
335\end{array}$ & $\begin{array}{l}2,052, \\
496\end{array}$ & 2,056, & 2,037, \\
\hline $\begin{array}{l}\text { Migrants } \\
\text { between } \\
\text { municipalities }\end{array}$ & 19,674 & 22,259 & 19,201 & 26,460 & 27,204 & 77,334 & 87,084 & 90,339 & 90,092 \\
\hline $\begin{array}{l}\text { Crude Migration } \\
\text { Intensity (CMI) }\end{array}$ & 0.99 & 1.12 & 0.96 & 1.32 & 1.35 & 3.79 & 4.24 & 4.39 & 4.42 \\
\hline $\begin{array}{l}\text { Migration } \\
\text { Efficiency Index } \\
\text { (MEI) }\end{array}$ & 21.69 & 20.38 & 19.60 & 16.58 & 16.60 & 8.26 & 4.93 & 5.04 & 4.01 \\
\hline $\begin{array}{l}\text { Aggregate Net } \\
\begin{array}{l}\text { Migration Rate } \\
\text { (ANMR) }\end{array}\end{array}$ & 0.21 & 0.23 & 0.19 & 0.22 & 0.22 & 0.31 & 0.21 & 0.22 & 0.18 \\
\hline $\begin{array}{l}\text { Mean migration } \\
\text { distance [km] }\end{array}$ & 27.82 & 27.33 & 30.17 & 29.52 & 29.41 & 41.67 & 42.35 & 41.66 & 42.65 \\
\hline $\begin{array}{l}\text { Index of } \\
\text { connectivity }\end{array}$ & 0.10 & 0.10 & 0.10 & 0.12 & 0.11 & 0.22 & 0.24 & 0.24 & 0.24 \\
\hline
\end{tabular}

Source: Authors' work, SMA (2017), SORS (2017b, c) 
The statistics change significantly in 2008 since all the inhabitants of the Republic of Slovenia were considered in the statistical reports and analyses, rather than exclusively its citizens. From the table, it is obvious that, in general, all other analysed statistics increase over time, except for MEl and consequently ANMR, which decrease over time (and considering two different periods before and after 2008). In 2009, the migration distance grew, which indicates that foreigners in Slovenia migrate over longer distances than citizens. The mean migration distance in the analysed the year 2014 was app. 42.5 kilometres, which indicates migration over mid-long distances, and not only between two adjacent municipalities (the area of an average municipality was app. $96 \mathrm{~km} 2$ (SORS, 2017b); if we presumed a circle municipality, the radius would be app. $5.5 \mathrm{~km})$.

The $C M I$, which measures the propensity to move, is very low: only app. $4 \%$ in the last years, but it was only approximately $1 \%$ before 2008. Our results on CMI are in line with other international results. Recently, Bell et al. (2015) compared migration intensities for 96 countries around the world. Their results confirmed the wide variation in migration intensities across the world, ranging from just $1 \%$ in Macedonia to $19 \%$ in Iceland. Slovenia recorded the fifth-lowest intensity in the sample (Bell et al., 2015).

The results of the analyses of $C M I, M E I$, and $A N M R$ at different spatial levels proved that $C M I$ and $A N M R$ are dependent on the spatial scale, whereas there is a very small variation in the MEI with changes in the geographical scale; see Figure 3 . This is especially valid for the last period when all the inhabitants are included in the analysis, and for smaller ASRs. Again, our results are in line with the international literature. Namely, Rees et al. (2016) and Bernard et al. (2017) reported that the CMI rises steadily as the ASR count increases, whereas the MEI is stable and largely scale independent above a threshold of 20 ASRs. Therefore, we conclude that the overall migration efficiency in Slovenia is decreasing. This means that migration streams and counterstreams are, independently of the spatial scale, more and more closely balanced. This can be seen also from Figure 1, where the net migration rate for all other municipalities, except for Ljubljana and Maribor, is not higher than $0.012 \%$ of total Slovenian population.

The previous conclusion can also be proven by the results of the correlation analysis between the Human Development Index and the migration intensity in the country. Separate consideration of two-time series shows that there is a strong correlation (Pearson coefficient of correlation for 2000-2007 is 0.97 and for 2008-2014 is 0.83) and that migration intensity decreases with the human development conditions in Slovenia; see Figure 4. We also presented MEI according to HDI for Slovenia in 2002 comparing to results from Rees et al. $(2016)$, who compared HDI and MEI for 47 countries all around the world. In Figure 5, Slovenia is located near Spain and France showing that migration intensity (and its variation) is much lower in the countries with high HDI than in those with lower HDI. Nevertheless, MEI for Slovenia is the highest comparing the Slovenian, French and Spanish spatial imbalance between migration flows and counter-flows. 
Figure 3

The Migration Intensity (CMI), Migration Effectiveness (MEI), and Aggregate Net Migration Rate (ANMR), as a Function of the Number of Aggregated Spatial Regions (ASRs), Internal Migrations between Municipalities in Slovenia in 2000-2014
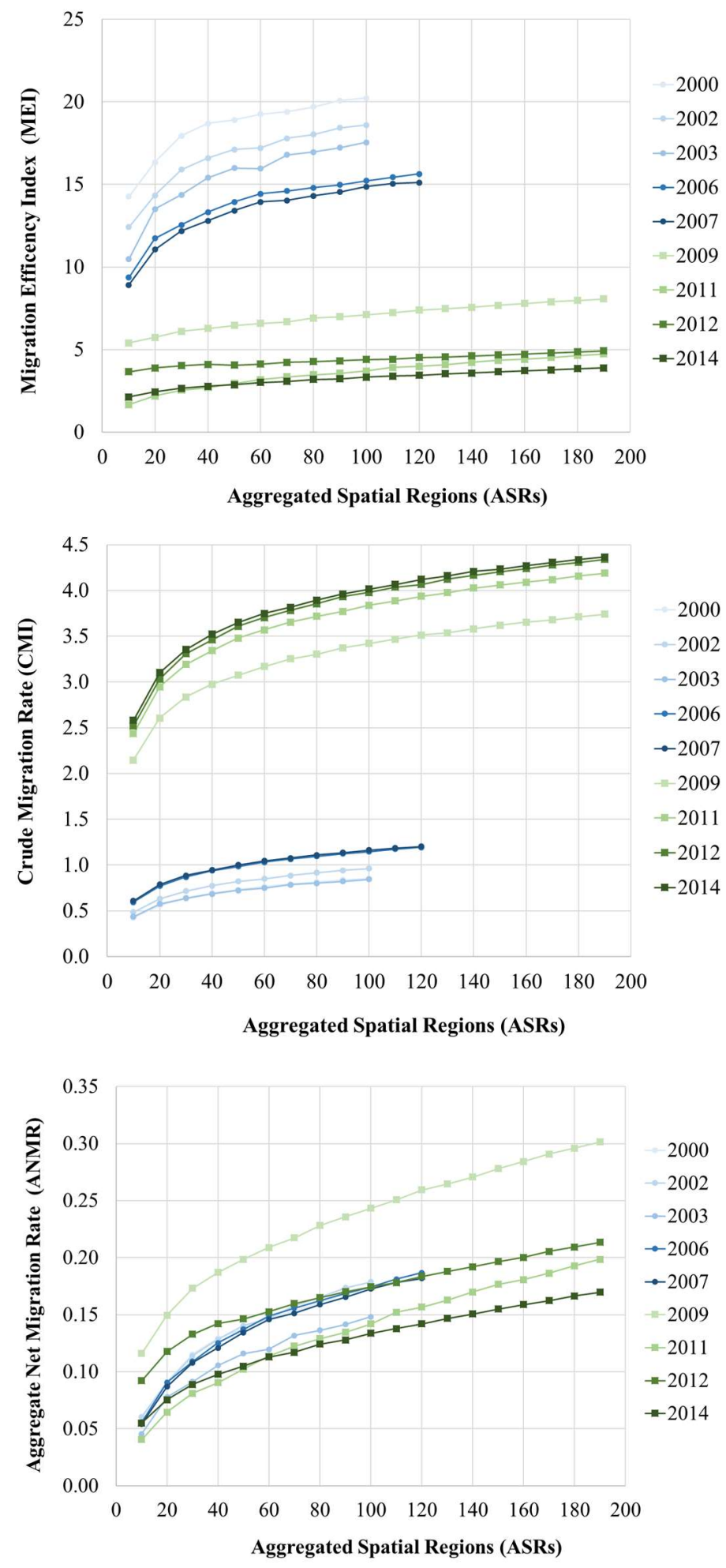

Source: Authors' work, SORS (2017b).

Note: Not all results for the period of 2000-2007 could be calculated because of the very low connectivity in the matrix, see also Tab. 1 
Figure 4

Migration Effectiveness Index (MEI) and the Human Development Index (HDI), Internal Migrations between Municipalities in Slovenia in 2000-201 4

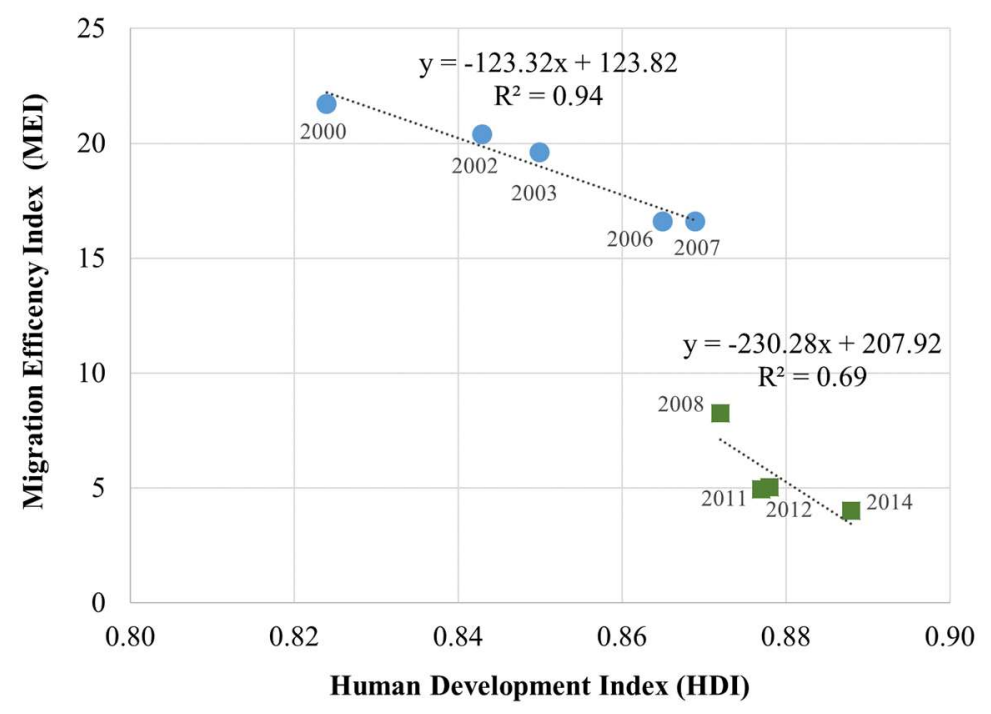

Source: Authors' work, SORS (2017b).

Figure 5

Migration Effectiveness Index (MEI) and the Human Development Index (HDI) for 47 Countries (data from the 2000 round censuses) and Slovenia (data for the 2002 census)

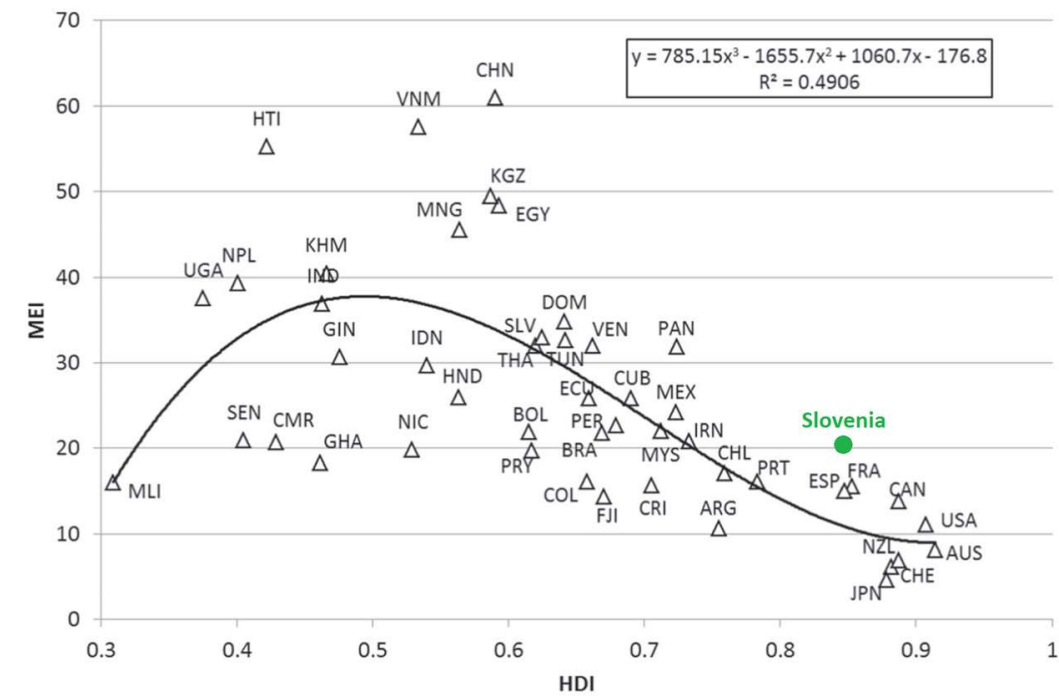

Source: Rees et al. (2016: 14), Authors' calculations, SORS (2017b), UN (2016). Note that the results on regression analysis apply to all other data except for Slovenia.

\section{Discussion and conclusions}

In this paper, we analysed the impact of migrations between municipalities on population redistribution in Slovenia. The analysis was restricted for the period between 2000 and 2014. In that time, the number of municipalities in the country changed several times, which has reflected in the analysed data. For this reason, we used a bespoke software, the IMAGE Studio (Daras, 2014; Stillwell et al., 2014), which had been designed to compute a suite of migration indicators and simultaneously 
explored the effects of the Modifiable Areal Unit Problem on cross-national and crosstime comparisons of migration. The migration flows at various levels of spatial scale were examined, and the redistributive effects of internal migration were analysed.

We found that, although the level of internal migration within Slovenia increases (crude migration index increases), the efficiency of migration as a mechanism for population redistribution is decreasing (migration effectiveness index decreases, i.e., migration streams and counter-streams of Slovenia are becoming more balanced). This is especially valid for the last period from 2008 on and for mid-and short-distance migrations.

Comparing the efficiency of migration for population distribution (migration effectiveness index) to human development in Slovenia (human development index) in the analysed period, we found that, according to the theoretical model of association between them (Rees et al., 2016), Slovenia has already reached its peak of population distribution regarding the migration. We suppose that the peak had been reached before the analysed period (before the year 2000) because the Slovenian migration efficiency index has been decreasing all the time since 2000.

Rees et al. (2016) compared the efficiency of migration for population distribution to human development in almost 50 countries all around the globe. Comparing data for Slovenia to the results for the countries considered by Rees et al. (2016), we found similarities between France, Spain, and Slovenia regarding human development and population distribution. However, although the human development index is similar for the three countries, the Slovenian migration effectiveness index is the highest. This means that the efficiency of migration for population distribution in Slovenia is higher than in France and Spain.

The IMAGE Studio (Daras, 2014; Stillwell et al., 2014) has proven to be a very suitable tool for different migration analyses. In this paper, we analysed the propensity to migrate and the efficiency of migration for Slovenian population distribution. However, for our future research, the analysis of the impact of distance on migration is seen as one of the most promising issues.

\section{References}

1. Bell, M., Blake, M., Boyle, P., Duke-Williams, O., Rees, P., Stillwell, J., Hugo, G. (2002), "Crossnational comparison of internal migration: Issues and measures", Journal of the Royal Statistical Society: Series A (Statistics in Society), Vol. 165, No. 3, pp. 435-464.

2. Bell, M., Charles-Edwards, E., Kupiszewska, D., Kupiszewski, M., Stillwell, J., Zhu, Y. (2015), "Internal migration and development: Comparing migration intensities around the world", Population and Development Review, Vol. 41, No. 1, pp. 33-58.

3. Bernard, A., Bell, M., Charles-Edwards, E. (2014), "Improved measures for the cross-national comparison of age profiles of internal migration", Population Studies, Vol. 68, No. 2, pp. 179195.

4. Bernard, A., Rowe, F., Bell, M., Ueffing, P., Charles-Edwards, E. (2017), "Comparing internal Migration across the Countries of Latin America: A Multidimensional Approach", PLOS ONE, Vol. 12, No. 3.

5. Bevc, M., Zupančič, J., Lukšič-Hacin, M. (2004), "Migracijska politika in problem bega možganov" (Migration politics and brain drain problem), available at: http://www.slovenijajutri.gov.si/fileadmin/urednik/dokumenti/MBevc.pdf (25 March 2017).

6. Daras, K. (2014), "Image Studio 1.4.2 User Manual", available at: https://www.archive.gpem.ua.edu.au/docs/acpr/IMAGE_studio_user_manual.pdf (15 December 2017).

7. Drobne, S., Rajar, T., Lisec, A. (2013), "Dynamics of migration and commuting to the urban centres of Slovenia, 2000-201 1" (Dinamika selitev in delovne mobilnosti v urbana središča Slovenije, 2000-2011), Geodetski vestnik, Vol. 57, No. 2, pp. 313-353, available at: http://www.geodetski-vestnik.com/images/57/2/gv57-2_drobne_eng.pdf 
(15 December 2017).

8. HDI (2018), "Human Development Index - Wikipedia", available at: https://en.wikipedia.org/wiki/Human Development Index (12 October 2018).

9. Openshaw, S. (1984), The Modifiable Areal Unit Problem, Geo Books, Norwich, available at: http://amrg.org.uk/catmog/ (15 August 2015).

10. Ravbar, M. (2005), "Urban sprawl: Popačena slika (sub)urbanizacije v Sloveniji?" (Urban sprawl: Skewed picture of (sub)urbanization in Slovenia?), Geografski vestnik, Vol. 77, No. 1, pp. 27-36.

11. Rees, P., Bell, M., Kupiszewski, M., Kupiszewska, D., Ueffing, P., Bernard, A., Charles-Edwards, E., Stillwell, J. (2016), "The impact of internal migration on population redistribution: an international comparison", Population, Space and Place, Vol. 23, No. 6.

12. SMA (2017), "Spatial data on municipalities in Slovenia in 2000-2016", The Surveying and Mapping Authority of the Republic of Slovenia, SMA.

13. SORS (2017a), "Methodological Explanations. Migrations", Statistical Office of the Republic of Slovenia, SORS, available at: http://www.stat.si/statweb/File/DocSysFile/9519 (15 August 2017).

14. SORS (2017b), "Migration change of population, municipalities, Slovenia, annually. SI-STAT, Database", The Statistical Office of the Republic of Slovenia, SORS, available at: http://pxweb.stat.si/pxweb/Dialog/varval.asp?ma=05I2002E\&ti=\&path=../Database/Dem ographics/05_population/25_Migration_Change/10_05l20_Migration_Change/\&lang=1 (15 August 2017).

15. SORS (2017c), "Population by large and 5-year age groups and sex, municipalities, Slovenia, half-yearly. SI-STAT, Database", The Statistical Office of the Republic of Slovenia, SORS, available at:

http://pxweb.stat.si/pxweb/Dialog/varval.asp?ma=05C4004E\&ti=\&path=../Database/De mographics/05_population/10_Number_Population/20_05C40_Population_obcine/\&lang =1 (15 August 2017).

16. Stillwell, J., Daras, K., Bell, M., Lomax, N. (2014), "The IMAGE Studio: A tool for internal migration analysis and modelling", Applied Spatial Analysis and Policy, Vol. 7, No. 1, pp. 523.

17. Stillwell, J., Bell, M., Ueffing, P., Daras, K., Charles-Edwards, E., Kupiszewski, M., Kupiszewska, D. (2016), "Internal migration around the world: comparing distance travelled and its frictional effect", Environment and Planning A, Vol. 48, No. 8, pp. 1657-1675.

18. UMAR (2009), "Socialni razgledi 2008 (Social views 2018)", Urad Republike Slovenije za makroekonomske analize in razvoj / Institute of Macroeconomic Analysis and Development, UMAR, available at:

http://www.umar.gov.si/fileadmin/user_upload/publikacije/socrazgledi/2009/socialni_raz gledi_2009.pdf (15 December 2017).

19. UN (2017), "United Nations Development Programme UNDP", United Nations Programme Human Development Reports, available at: http://hdr.undp.org/en/countries/profiles/SVN (15 August 2017). 


\section{About the authors}

Samo Drobne is an assistant professor at the Department of Geodetic Engineering, Faculty of Civil and Geodetic Engineering (FGG), University of Ljubljana (UL). His main research fields include spatial systems, operations research, geographical information systems, and spatial analysis and statistics. Currently, he is a vice-dean for educational affairs at UL FGG. More information about him is available at http://fgg-web.fgg.unilj.si/ /sdrobne/. The author can be contacted at samo.drobne@fgg.uni-lj.si.

Urška Drešček is a young researcher at the Department of Geodetic Engineering, Faculty of Civil and Geodetic Engineering (FGG), University of Ljubljana (UL). Her main research fields include photogrammetry, spatial data modelling and spatial analysis. The author can be contacted at urska.drescek@fgg.uni-lj.si. 